\title{
Comparative evaluation of artificial rupture of membranes and spontaneous rupture of membranes on course of labour and feto-maternal outcomes
}

\author{
Anjali Chauhan*, Bani Sarkar, Kritika Tanwar
}

\begin{abstract}
Department of Obstetrics and Gynaecology, Atal Bihari Vajpayee Institute of Medical Science and Dr. Ram Manohar Lohia Hospital, New Delhi. India
\end{abstract}

Received: 26 July 2020

Accepted: 05 September 2020

\author{
*Correspondence: \\ Dr. Anjali Chauhan, \\ E-mail: anjalich892@gmail.com
}

Copyright: (C) the author(s), publisher and licensee Medip Academy. This is an open-access article distributed under the terms of the Creative Commons Attribution Non-Commercial License, which permits unrestricted non-commercial use, distribution, and reproduction in any medium, provided the original work is properly cited.

\begin{abstract}
Background: Present study was undertaken to do a comparative evaluation of artificial rupture of membrane (ARM) and spontaneous rupture of membrane (SRM) on the course of labour and feto-maternal outcome.

Methods: It was prospective interventional randomized comparative study including 120 primigravidae (60 in ARM and SRM group each) with cervical dilatation $\geq 3 \mathrm{~cm}$ and intact membranes. Amniotomy was performed in ARM group after enrolment while no intervention in SRM group. Outcomes noted were duration of labor, mode of delivery, APGAR score, NICU stay.

Results: Significant reduction seen in duration of labour in ARM group ( $p=0.0001)$. Mean duration of labor was 5.24 hours in ARM group while 6.94 hours in SRM group. No significant difference noted in mode of delivery $(p=0.082)$. No significant adverse feto-maternal outcomes were seen with amniotomy. APGAR score and NICU admission had no significant difference among the two groups.

Conclusions: ARM can be opted as an intervention with shorter duration of labour without adversely affecting the feto-maternal outcomes. It is safe, reliable and cost effective modality when employed in primigravida and may be considered as a low-cost accessible intervention to reduce prolonged labour and its associated complications.
\end{abstract}

Keywords: Amniotomy, ARM, Labour, SRM

\section{INTRODUCTION}

The primary aim of intrapartum obstetric care is to deliver healthy babies to healthy mothers with minimum adverse effects. This objective is achieved by close monitoring of maternal and fetal conditions during labour with appropriate interventions when necessary. One of these interventions introduced in labour management is the artificial rupture of fetal membranes (amniotomy/ ARM) in labour for augmentation of labour without adverse feto-maternal outcomes. Amniotomy is the most common intervention in modern obstetrics and influences the overall management of intrapartum obstetric care. Ruptured membranes, done for induction and for augmentation of labour, improves progress of labour and shortens labour. It facilitates detection of meconium and blood to alert the obstetricians, enables better intrapartum surveillance. Many obstetrician advocates artificial rupture of membranes on the belief that it increases uterine contractions and therefore improves the labour progress importantly in cases of prolong labour. It is believed that after rupture of membranes there is increased production of prostaglandins with oxytocin which acts on uterus to cause stronger uterine contractions and promotes cervical dilatation. Prolonged labour causes increased maternal morbidity and mortality. According to WHO 2015, approximately half a million women died annually in labour. ${ }^{1}$ Haemorrhage and infection, which are strongly associated with prolong labour, are the significant cause of mortality. ${ }^{2}$ For this 
reason, amniotomy may be of particular benefits to patients in the developing world. On the other hand, it may be associated with increased risks of fetal heart rate abnormalities, cord prolapse, infection, and dry labour. Thus with the merits and demerits of ruptured membranes and the controversial and conflicting reports on routine versus selective amniotomy for induction or augmentation of labour, there are many questions to ponder: 1) Is it worth performing amniotomy for augmentation of labour, when labour is progressing normally and FHR is normal? 2) Is amniotomy justified in active management of normal labour? 3) What is the advantage of shorter labour compared to increased risk of fetal distress? 4) What is the optimum time for ARM? 5) Is obstetrician's desire and impulse to hurry labour is justified, if so when?

There is no uniform consensus made regarding artificial rupture of membranes. The present study was undertaken, to evaluate the outcome of labour in terms of duration, mode of delivery and fetal outcomes which includes APGAR score, NICU stay in the patients with artificial rupture of membrane and to compare it with spontaneous rupture of membrane (SRM).

\section{METHODS}

This was a prospective interventional randomized comparative study conducted at Dr. RML Hospital and ABVIMS, New Delhi between November 2017 and March 2019. Study included total of 120 term primigravidae fulfilling the inclusion and exclusion criteria who were admitted in the labour room with PV findings of cervical dilatation $\geq 3 \mathrm{~cm}$ and intact membranes in labour. Written Informed consent in patient's own language was taken from all enrolled patients explaining about the procedure with risks and benefits of the intervention. Study group was divided into two groups by random allocation (sealed envelope method):

GROUP I: ARM- Artificial rupture of membrane was done at the time of enrolment with cervical dilatation $\geq 3 \mathrm{~cm}$ for augmentation of labour $(n=60)$.

GROUP II: SRM- Allowed for spontaneous rupture of membrane in labour $(\mathrm{n}=60)$.

\section{Inclusion criteria}

Term primigravidae in labour (with cervical dilatation $\geq 3$ $\mathrm{cm}$ ) with intact amniotic membranes with singleton pregnancy, cephalic presentation with adequate pelvis.

\section{Exclusion criteria}

Women with gestation $<37$ weeks, PROM, Obstetric risk factors like- antepartum hemorrhage, previous LSCS, scarred uterus. HIV positive patients, an active perineal herpes simplex viral infection were excluded. Patients recruited in Group II if undergoes ARM when indicated during progress of labour were also excluded from the study.

A detailed history, complete general examination, per abdominal and pelvic examination was done. Fetal heart rate and contractions were monitored. In the ARM group, before amniotomy was performed, the engagement of the head was assessed to prevent the cord prolapse. Under all aseptic precautions, membranes were ruptured using Kocher's forceps. Colour of liquor was noted. Fetal heart rate was recorded before and after the procedure. Labour was monitored. Oxytocin augmentation was done in patients with inadequate uterine contractions. Duration of labour was noted from the time of enrolment to delivery time, method of delivery was noted. Soon after delivery babies APGAR score, birth weight, need for NICU admission were noted.

Similarly labour was monitored in patients with spontaneous rupture of membrane group and fetomaternal outcomes were noted.

\section{Statistical analysis}

Categorical variables were presented in number and percentage $(\%)$ and continuous variables were presented as mean \pm SD and median. Normality of data was tested by Kolmogorov-Smirnov test. If the normality was rejected then non parametric test was used.

Statistical tests were applied as follows- 1) Quantitative variables were compared using Independent $t$ test/MannWhitney Test (as the data sets were not normally distributed) between the two groups. 2) Qualitative variables were correlated using Chi-Square test/Fisher's Exact test.

A $p$ value of $<0.05$ was considered statistically significant. The data was entered in MS EXCEL spreadsheet and analysis was done using Statistical Package for Social Sciences (SPSS) version 21.0.

\section{RESULTS}

\section{Descriptive characteristics of study population}

Participant's basic characteristics such as age groups, BMI, parity, gestational age were near similar between the two groups. The mean age of study population in ARM group and SRM group was 25.47 years and 26.43 years respectively. The mean BMI of the study group ARM and SRM was 23.05 and 22.98 respectively. Minimum BMI was 16 and maximum was 27. The mean gestational age in weeks in both the groups were similar i.e. 38 weeks of gestation. Total $45 \%$ patients in ARM group and $36.67 \%$ patients in SRM group were induced with PGE2 (dinoprostone agent) before they were enrolled in the study. While 55\% patients in ARM group 
and $63.33 \%$ patients in SRM had spontaneous onset of labour.

\section{Duration of labour}

In the present study, there is a significant reduction in the duration of labour in patients with artificial rupture of membranes compared to spontaneous rupture of membranes $(\mathrm{p}=0.0001)$. Mean duration of labour was 5.24 hours in ARM group compared to 6.94 hours in SRM group. Amniotomy has been related with significant shortened duration of labour which has been reported in different studies.

Table 1: Mean duration of labour in ARM and SRM group.

\begin{tabular}{|lll|}
\hline & ARM & SRM \\
\hline Sample size & 54 & 57 \\
\hline Mean \pm SD & $5.24 \pm 2.5$ & $6.94 \pm 1.8$ \\
\hline Median & 5.13 & 7 \\
\hline Min-max & $0.4-10$ & $3.34-11.5$ \\
\hline $\begin{array}{l}\text { Inter quartile } \\
\text { range }\end{array}$ & $3.400-7.100$ & $6.070-8.163$ \\
\hline
\end{tabular}

Thus, the difference in time to delivery across the patients undergoing amniotomy than with spontaneous rupture of membranes may encourage less monitoring time, decrease in the staff of a labour and delivery unit, shorter hospital stay in addition to the expected enhancement in patient satisfaction with shorter labour.

\section{Mode of delivery}

In the present study, there was no statistically significant difference in the mode of delivery among two groups $(\mathrm{p}=0.082)$. The results show a trend towards an increase in the risk of a caesarean section, though not statistically significant, in women who had an amniotomy $(\mathrm{p}=0.491)$. The occurrence of instrumental deliveries was found to be more in patients with spontaneous rupture of membranes, but this difference was also not statistically significant $(\mathrm{p}=0.119)$. Since the sample size of the present study was small, there is a need for a large sample multicenter collaborative study to clarify these findings.

Table 2: Mode of delivery in ARM and SRM groups.

\begin{tabular}{|llll|}
\hline & ARM & SRM & Total \\
& $\mathbf{N}(\%)$ & $\mathbf{N}(\%)$ & $\mathbf{N}(\%)$ \\
\cline { 1 - 3 } Vaginal & 54 & 53 & 107 \\
delivery & $(90.00)$ & $(88.33)$ & $(89.17)$ \\
\hline Instrumental & $0(0.00)$ & $4(6.67)$ & $4(3.33)$ \\
\cline { 1 - 3 } Caesarean & $6(10.00)$ & $3(5.00)$ & $9(7.50)$ \\
\cline { 1 - 3 } Total & $60(100)$ & $60(100)$ & $\begin{array}{l}120 \\
(100)\end{array}$ \\
\hline
\end{tabular}

\section{APGAR score}

In the present study, there was no statistical difference in the APGAR score at 1 minute in both the groups with only 2 patients and 1 patient in ARM and SRM groups with their babies born with APGAR score <7. While all babies had APGAR score $>7$ at 5 minutes in both the groups.

Table 3: APGAR score at 1 minute in ARM and SRM groups.

\begin{tabular}{|llll|} 
& $\begin{array}{l}\text { ARM } \\
\mathbf{N}(\%)\end{array}$ & $\begin{array}{l}\text { SRM } \\
\mathbf{N}(\%)\end{array}$ & $\begin{array}{l}\text { Total } \\
\mathbf{N}(\%)\end{array}$ \\
\cline { 1 - 4 } $\begin{array}{l}\text { APGAR } \\
<7\end{array}$ & $2(3.33)$ & $1(1.67)$ & $3(2.50)$ \\
\cline { 1 - 1 } $\begin{array}{l}\text { APGAR } \\
\geq 7\end{array}$ & $\begin{array}{l}58 \\
(96.67 \%)\end{array}$ & $\begin{array}{l}59 \\
(98.33 \%)\end{array}$ & $\begin{array}{l}117 \\
(97.50)\end{array}$ \\
\hline Total & $60(100)$ & $60(100)$ & $120(100)$ \\
\hline
\end{tabular}

\section{NICU stay}

In the present study, there was no significant difference in the NICU or special care nursery admission of babies born in both groups $(\mathrm{p}=1.00)$. There were 5 babies admitted for respiratory distress and 4 for jaundice.

Table 4: NICU admission in ARM and SRM groups.

\begin{tabular}{|llll|}
\hline NICU & ARM & SRM & Total \\
admission & $\mathbf{N}(\%)$ & $\mathbf{N}(\%)$ & $\mathbf{N}(\%)$ \\
\hline No & 55 & 56 & 111 \\
& $(91.67)$ & $(93.33)$ & $(92.50)$ \\
\hline Yes & $5(8.33)$ & $4(6.67)$ & $9(7.50)$ \\
\cline { 1 - 4 } Total & $60(100)$ & $60(100)$ & $120(100)$ \\
\hline
\end{tabular}

No case of umbilical cord prolapse was observed in the present study despite the possible causal relationship it appears to have with amniotomy.

There was no maternal or fetal mortality found in the present study.

\section{DISCUSSION}

Aim to provide better intrapartum obstetric care by the means of effective obstetric services helps in reducing maternal morbidity and mortality, especially in developing countries. The present study was undertaken to do a comparative evaluation of ARM and SRM on the course of labour and feto-maternal outcome. Although, amniotomy is a component of active management of labour aim to reduce rate of caesarean section for prolonged labour, or dystocia, its effect on the duration of labour has not been consistent. Evidence does not support routine amniotomy for all women. In some centres it is advocated and performed routinely in all women, and in many centres it is used for women whose labours have 
become prolonged. This depicts the lack of consensus regarding role of amniotomy.

The present study was compared with many other studies conducted in India as well as abroad. The present study results were supported by Bala et al, Livinus et al, Rasheed et al, Saadia, Cooney et al, Weis et al, Majeed et al, Macones et al, Bellad et al, all of which showed significant reduction in the duration of labour. ${ }^{3-11}$ The results were in contrast to Cochrane recent systemic reviews of 15 studies involving 5583 women which noted no statistically significant reduction in the length of the first and second stage of labour. ${ }^{12}$ While most studies did not found significant adverse feto-maternal side effects.

Thus, the difference in time to delivery across the patients undergoing amniotomy than with spontaneous rupture of membranes may encourage less monitoring time, decrease in the staff of a labour and delivery unit, shorter hospital stay in addition to the expected enhancement in patient satisfaction with shorter labour.

Major limitation in the present study was small sample size and restriction of the study to low risk primigravidae. This study could only measure time from enrolment to delivery interval because of the difficulty in determining the exact time at which a cervix is fully dilated, thus duration of first and second stage were not determined separately.

\section{CONCLUSION}

A significant reduction in the duration of labour is seen when ARM was done compared to SRM during labour. No significant difference was observed in the mode of delivery. There were no significant adverse feto-maternal outcomes seen with ARM. APGAR score and NICU admission had no significant difference among the two groups. Thus artificial rupture of membrane is safe, reliable and cost effective modality when employed in primigravida and may be considered as a low-cost accessible intervention to reduce prolonged labour and its associated complications, which has a practical implication in low resourced settings, without adversely affecting the feto-maternal outcomes.

\section{ACKNOWLEDGMENTS}

Authors are thankful to the head of the department for helping in the research work.

\section{Funding: No funding sources}

Conflict of interest: None declared

Ethical approval: This study was approved by the Institutional Ethics Committee. F.No. TP (MD/MS) (37/2017) /IEC/PGIMER/RMLH 1780/17. This article does not contain any studies with animals performed by any of the authors

\section{REFERENCES}

1. Bongaarts, J. WHO, UNICEF, UNFPA, World Bank Group, and United Nations Population Division. Trends in Maternal Mortality: 1990 to 2015 Geneva: World Health Organization, 2015. Popul Develop Rev. 2016;42(4):726-6.

2. Neilson JP, Lavender T, Quenby S, Wray S. Obstructed labour. Br Med Bull. 2003;67:191-204.

3. Bala A, Bagga R, Kalra J, Dutta S. Early versus delayed amniotomy during labour induction with oxytocin in women with Bishop's score of $\geq 6$ : a randomized trial. J Matern Fetal Neonat Med. 2018;31(22):2994-3001.

4. Onah LN, Dim CC, Nwagha UI, Ozumba BC. Effect of early amniotomy on the outcome of spontaneous labour: a randomized controlled trial of pregnant women in Enugu, South-east Nigeria. Afr Health Sci. 2015;15(4):1097-103.

5. Rasheed FA, Ahmed AA, Hussain SA. The impact of early versus late amniotomy on duration of labour, maternal and neonatal outcomes in Iraqi Primigravida with spontaneous labour. Med Sci. 2014;3(3):1343-51.

6. Saadia Z. Rates and indicators for amniotomy during labour - a descriptive cross sectional study between primigravidas and gravida 2 and above. Med Arch. 2014;68(2):110-2.

7. Cooney LG, Bastek JA. The association between early artificial amniotomy and chorioamnionitis in nulliparous induction of labour. Int Sch Res Notices. 2014;2014(628452):1-8.

8. Wei S, Wo BL, Qi HP, Xu H, Luo ZC, Roy C, et al. Early amniotomy and early oxytocin for prevention of, or therapy for, delay in first stage spontaneous labour compared with routine care. Cochrane Database Syst Rev. 2013;7(8):CD006794.

9. Majeed N, Tariq S. Comparison of artificial rupture of membranes with intact membrane in labouring multigravidae. J Rawalpindi Med Coll. 2013;17(2):234-7.

10. Macones GA, Cahill A, Stamilio DM, Odibo AO. The efficiency of early amniotomy in nulliparous labour induction: a randomized controlled trial. Am J Obstet Gynecol. 2012;207(5):403.e1-5.

11. Bellad MB, Kamal P, Rajeshwari P. Does artificial rupture of membrane (ARM) reduce duration of labour in primigravidae: a randomized controlled trial. South Asian Fed Obstet Gynecol. 2010;2(1):379.

12. Smyth RM, Alldred SK, Markham C. Amniotomy for shortening spontaneous labour. Cochrane Database Syst Rev. 2013;(6):CD006167.

Cite this article as: Chauhan A, Sarkar B, Tanwar $\mathrm{K}$. Comparative evaluation of artificial rupture of membranes and spontaneous rupture of membranes on course of labour and feto-maternal outcomes. Int J Reprod Contracept Obstet Gynecol 2020;9:4160-3. 